\title{
Cross-Cultural Training and Engineering: An Illustration Using Vietnamese Engineering Faculties' Responses to Nature of Engineering Instrument (Work in Progress)
}

\author{
Amanda Vazquez, University of Nevada, Las Vegas
}

Amanda Vazquez is a fourth-year mechanical engineering undergraduate student at the University of Nevada, Las Vegas. She is working as a research mentee under the R.A.M.P. (Research and Mentorship Program) at UNLV. This research is focused on Nature of Engineering View's of Professional Engineers. Prior to the R.A.M.P. program she worked on NSF EPSCoR STEM K-12 outreach programs, including: a STEM career program (SISTEM), portable lab equipment, and Summer teacher training programs.

\section{Ms. Erica J. Marti, University of Nevada, Las Vegas}

Erica Marti completed her PhD in Civil and Environmental Engineering at the University of Nevada, Las Vegas (UNLV). She holds a Master of Science in Engineering and Master of Education from UNLV and a Bachelor of Science in chemistry from the University of Illinois at Urbana-Champaign. Prior to graduate studies, Erica joined Teach for America and taught high school chemistry in Las Vegas. While her primary research involves water and wastewater, she has strong interests in engineering education research, teacher professional development, and secondary STEM education.

\section{Mr. Erdogan Kaya, University of Nevada, Las Vegas}

Kaya is a $\mathrm{PhD}$ candidate in science education at University of Nevada, Las Vegas. He is working as a research assistant and teaching science methods courses. Prior to beginning the PhD program, he received his MS degree in computer science and engineering and holds a BS degree in chemical engineering. He taught K-12 STEM+CS for seven years. Additionally, he coached robotics teams and was awarded several grants that promote Science, Technology, Engineering, and Mathematics (STEM) and Computer Science(CS) education. He is also interested in improving STEM+CS education for minorities. He has been volunteering in many education outreach programs including Science Fair and Robotics programs such as First Robotics competitions. Areas of research interest include engineering education, STEM+CS, and robotics in K-12 education. Kaya advocates his view that research, teaching and learning are best practiced as a unified enterprise that benefits students and society. He has received numerous teaching awards as well as grants for his research from several foundations. Kaya is an active member of AERA, ASEE, ASTE, NARST, NSTA, SITE, SIGCSE, and CSTA, has presented at over 20 conferences, published in ranked journals (e.g. Journal of College Science Teaching), reviewed conference proposals (e.g ASEE) and manuscripts(e.g. NSTA Science Scope).

\section{Dr. Hasan Deniz, University of Nevada, Las Vegas}

Hasan Deniz is an Associate Professor of Science Education at University of Nevada Las Vegas. He teaches undergraduate, masters, and doctoral level courses in science education program at University of Nevada Las Vegas. His research agenda includes epistemological beliefs in science and evolution education. He is recently engaged in professional development activities supported by several grants targeting to increase elementary teachers' knowledge and skills to integrate science, language arts, and engineering education within the context of Next Generation Science Standards. 


\title{
Cross-Cultural Training and Engineering: an Illustration Using Vietnamese Engineering Faculties' Responses to Nature of Engineering Instrument (Work-In-Progress)
}

\begin{abstract}
Engineering faculty have advanced experiences with engineering that non-engineers do not have, but what Nature of Engineering (NOE) concepts do engineering researchers hold? For K12 engineering education, having an informed NOE understanding is an essential part of engineering literacy. Yet for the higher education engineering community, NOE is hardly ever discussed. Understanding engineering faculties' NOE views can be a valuable contribution to current NOE research. Our project is part of a collaboration between a southwestern US higher education institute and a Vietnamese University. The cohort of Vietnamese engineering faculty is participating in training for research in environmental engineering for three months in the US. Vietnamese faculty is expected to improve their research skills at the end of the comprehensive professional development under the training of US environmental engineering researchers. Over the three months, Vietnamese faculty will search literature, learn lab skills and conduct a selfdriven, lab-based research project in an environmental engineering lab. The purpose of our research is two-fold: Firstly, we will investigate what Vietnamese environmental engineering faculty say in response to the NOE instrument; secondly, the purpose of our study is to explicate the impact of a collaboration between a US university and a Vietnamese university. More specifically, our research study will identify NOE views of Vietnamese engineering faculty prior to and after training. While Nature of Engineering (NOE) views are increasingly growing stateside, it is equally important to look at the views of NOE globally. Following the Vietnamese faculty research experience with hands-on laboratory projects under US engineering research mentors, we will examine how Vietnamese engineers' NOE views have changed through interviews and open-ended written assessments. Although there are some attempts in assessing teachers' and students' NOE views, according to the authors' knowledge, there is no prior research which assessed NOE views of international engineering faculty in a higher education setting. In this work-in-progress research, we report the framework and anticipated outcomes of a pilot study on NOE understanding of Vietnamese faculty.
\end{abstract}

Keywords: Nature of Engineering, Engineering Education, Environmental Engineering, International Collaboration, NOE Instrument, Engineering Faculty 


\section{Introduction}

For the last 10 years, there is a continuous increase in the number of research attempts in engineering education, and a relatively increased growth in emphasis on Nature of Engineering (NOE) research $[1,2,3,4,5,6,7,8]$. Although still a developing area, a handful of NOE research findings demonstrate that instructors and students hold an inadequate understanding of NOE $[4,6]$. Nevertheless, training of teachers and students holds promise to improve learners' NOE understanding. Although there are some recommendations to place NOE instruction at the center of engineering education [2, 5, 9], it is still an emerging area, particularly in higher education.

In an effort to understand the NOE, Karatas et al. [4] made a thorough review of the literature of engineering, Hartman and Bell [3] conducted a Delphi study, and Deniz et al. [2] made a detailed review of Next Generation Science Standards (NGSS) and the K-12 Science Framework to develop a list of NOE aspects. Research comparison of the NOE items reveals many similarities among the NOE literature that NOE is the epistemology of engineering which are philosophical values and beliefs inherent to body of engineering knowledge. There was a broad consensus among the researchers about the NOE aspects for the development of NOE understanding that engineering is: subjective, creative, empirical, socially and culturally embedded. Two other important aspects are the distinction of criteria and constraints, and no universal engineering design process exists for doing engineering but all engineers follow a cyclical engineering design process. These researchers also underscored that it is important to acknowledge that engineering design is tentative and a social and collaborative field which requires teamwork. It is also important to recognize the similarities and differences between engineering and other disciplines such as science (see appendix A).

Currently, the extant NOE literature, which recently gained momentum due to the federal push in engineering education, only assesses the NOE ideas of K-12 teachers and students. While we appreciate the important contribution of the conducted research, we also underscore the necessity of understanding the NOE ideas of professional engineers (e.g. engineering researchers and higher education engineering instructors). Investigating engineering faculty's NOE views can play a significant role in contributing to our current understanding of NOE teaching and learning. Through our work-in-progress paper, we seek to understand Vietnamese engineering researchers' NOE views by assessing their NOE understanding with the NOE instrument and follow-up interviews.

\section{Literature Review}

NOE research is a relatively new research agenda which is growing exponentially with the release of recent engineering reform documents $[10,11]$. There are several studies investigating students' and teachers' NOE views [4, 5, 6, 7]. Karatas et al. [4], for example, conducted a study to examine first-year engineering students' NOE views through a modified version of the Views-of-Nature-Of-Science (VNOS) questionnaire [12]. The researchers found that engineering students held naive NOE views. More specifically, most students struggled to differentiate between science and engineering, and they illustrated engineering as applied science. Only a few students thought that there could be more than one solution for an 
engineering design problem and solutions are tentative. In another study, Karatas, Micklos and Bodner [5] examined 6th-grade students' NOE views through students' engineer- or engineersat-work drawings and semi-structured interviews. The study consisted of 20 students (10 male10 female), ages 11-12 years old that were close to the intellectual national average. Data was collected from 45-minute interviews held by 2 researchers. Semi-structured interviews included questions about students' definition of engineering, the demarcation between science and engineering, and the role of engineering in society. Researchers found that most students had difficulty explaining the differences between science and engineering, and relatively few students viewed engineering design as a dynamic process. Overall, authors reported that 6thgrade students held naive NOE views.

In another strand, Deniz et al. [13] investigated the NOE views of in-service elementary teachers who participated in an engineering teacher professional development during summer 2016 in a southwestern public university. Thirty teachers from a large urban area were included in this study from different teaching experience backgrounds and all had different levels of college science courses. The data consisted of open-ended questionnaires and interviews in the beginning and end of the study. Researchers analyzed the data by using a five-point scale and the data analyses of pre and post tests concluded that professional development increased teachers' NOE scores significantly.

Similarly, Deniz et al. [14] investigated the changes in elementary teachers' engineering teaching efficacy beliefs that participated in NOE teacher professional development during summer 2016 in a southwestern public university. Thirty elementary school teachers were included in this study from different teaching experience backgrounds and all had different levels of college science courses. The data was collected by using a modified version of the STEBI [15] instrument which included 23 Likert-scale items rated from 1- strongly agree to 5-strongly disagree. Elementary teachers' efficacy beliefs increased significantly toward engineering instruction after the professional development. Authors recommended that when learners understand NOE, it would increase learners' attitudes toward engineering and engineering knowledge. Additionally, they also emphasized that understanding NOE may positively influence students' engineering career decisions. Furthermore, they also suggest that NOE and Nature Of Science (NOS) are related and complement each other, specifically addressing the demarcation aspect. As a side note, they ended with a recommendation that NOE should be explicitly taught rather than implicitly.

In another study, Marti et al. [8] organized a graduate level summer course for in-service secondary science teachers. Teachers designed solar powered water heaters or water treatment systems by using the engineering design process. The course included explicit references to NOE aspects. Researchers adopted the NOE instrument [13] and conducted pre and post assessments to investigate teachers' NOE views. Results showed that teachers held incomplete or partially informed ideas about NOE in their case studies in the beginning of the course. However, teachers' NOE views improved at the end of the course.

Other studies also indicate that students and teachers hold incomplete NOE understanding. For example, Yesilyurt et al. [16] examined NOE understanding of elementary students and reported that students held a weak understanding of NOE as stated in pre-test findings. Deniz et al. [13] assessed 30 elementary teachers' NOE beliefs and found that teachers defined engineering synonymous with science according to pre-test results. In the study conducted by Kaya et al. [6], researchers investigated pre-service teachers' NOE views and found that pre-service elementary teachers hold weak NOE knowledge like in-service teachers. 
In contrast to the quantitative research conducted by Deniz et al. [13] and Kaya et al. [6], Marti et al. $[7,8]$ conducted qualitative case studies to assess teachers' NOE views. In examining two NOE studies $[13,8]$, it is apparent that secondary teachers held better understanding of NOE aspects when compared to the elementary teachers, but the secondary teachers still hold partially informed NOE views at the onset. On the other hand, training helps learners to improve their NOE views. At the end of the interventions, participants improved their NOE understanding in all the studies stated above.

Overall, most of the NOE research related to engineering education show similarities in NOE aspects and assessments independent of their research methodology. Researchers underscored that understanding these NOE aspects inform engineering literacy and NOE is an essential component of engineering education. However all the current NOE research was conducted for K-12 students or teachers. We believe that there is a research gap that needs to be studied to reveal engineering faculty's NOE views. Higher education instructors' engineering views influence their engineering teaching, which, in turn, influences engineering students' future engineering perceptions. Examining higher education instructors' NOE views is important to develop engineering education further. Specifically, understanding engineering faculties' NOE perceptions can provide a framework to modify current engineering courses and may assist in embedding NOE instruction in higher education settings.

\section{Research Questions}

There are two research questions that will guide our study:

1. Do the Vietnamese engineering faculty hold NOE views that are not aligned, partially aligned, or fully aligned with the previously articulated NOE aspects?

2. To what extent, if any, do Vietnamese engineering faculty's NOE views change after engineering professional development?

We will present the methodology and strategy to assess Vietnamese engineering faculties' NOE views in this work-in-progress study.

\section{Methods}

We adapted the validated NOE instrument, developed by Deniz et al. [13]. VNOE is an open-ended questionnaire that consists of 7 questions aimed at assessing learners' NOE understanding. In the modified version of the NOE, we added three more questions to address NOE aspects missing from the questionnaire, such as the social NOE aspect, added language to force participants to provide examples for each questionnaire item, and slightly rephrased one question to make it more universal. The modified instrument, as shown in Appendix B, has not been validated.

All the questionnaire items will be translated to Vietnamese by translators. The NOE instrument will be distributed to the Vietnamese faculty when they sign the consent form. Participants will have ample time to complete the written questionnaire. This will allow participants to reflect on their NOE views in-depth and relate the responses to their current work experiences. After receiving the written responses, we will conduct a follow-up interview with the participants to elaborate on their written responses to generate as much detail as possible on their NOE views. All NOE items will be used in conjunction with individual follow-up interviews with the Vietnamese engineering research and teaching faculty with the assistance of 
interpreters. Interpreters will translate the questions and the responses instantaneously. We expect each interview to last between 30-60 minutes. We are planning to conduct face-to-face or video conference interviews with the Vietnamese engineering researchers. The interviews will be audio recorded and transcribed verbatim by one researcher, and a second researcher will review the transcribed text for accuracy. If any clarification of the data will be necessary, follow-up emails will be carried out. Transcripts will be shared with the Vietnamese engineering researchers and the interpreters for confirmation and to reach higher accuracy in data.

We will conduct regular meetings to analyze the data. Predetermined NOE aspects (see Appendix A) will guide the coding of written and interview responses. After each response is scored based on the rubric (see Appendix C), authors will discuss to reach a consensus on the scoring, and final profiles of the participants will be generated by merging interview and written responses. Based on the data size, results will be reported either qualitatively as descriptive statements, or statistical paired t-test will be employed to compare pre-test and post-test NOE responses of the Vietnamese engineering faculty.

\section{Anticipated Outcomes}

This study will examine engineering faculty NOE understanding, and it will present a description of their epistemological beliefs of engineering. Our research will contribute to overall understanding of professional engineers' NOE views. We expect engineering faculty to hold informed views of engineering; however, it is just an assumption. If they do not, we will explore the effectiveness and influence of a professional development on faculty's NOE views. According to research, scientists do not always think and reflect about the philosophical values and assumptions of their work [18]. It might be the case for engineers as well. We are planning to empirically test this assumption to understand engineering faculty's NOE views.

\section{REFERENCES}

[1] Cunningham, C. M., \& Kelly, G. J. (2017). Epistemic practices of engineering for education. Science Education, 101(3), 486-505.

[2] Deniz, H., Yesilyurt, E., Newman, J. S., \& Kaya, E., (in press). Towards Defining Nature of Engineering in the Next Generation Science Standards Era. Critical Issues in STEM Education.

[3] Hartman, B., \& Bell, R. L. (2017, June), Teaching the Nature of Engineering in K-12 Science Education: A Delphi Study (Fundamental) Paper presented at 2017 ASEE Annual Conference \& Exposition, Columbus, Ohio. https://peer.asee.org/28927

[4] Karataş, F. Ö., Bodner, G. M., \& Unal, S. (2016). First-year engineering students' views of the nature of engineering: implications for engineering programmes. European Journal of Engineering Education, 41(1), $1-22$.

[5] Karatas, F. O., Micklos, A., \& Bodner, G. M. (2011). Sixth-grade students' views of the nature of engineering and images of engineers. Journal of Science Education and Technology, 20(2), 123-135.

[6] Kaya, E., Newley, A., Deniz, H., Yesilyurt, E., \& Newley, P. (2017). Introducing Engineering Design to a Science Teaching Methods Course Through Educational Robotics and Exploring Changes in Views of Preservice Elementary Teachers. Journal of College Science Teaching, 47(2).

[7] Marti, E. J., \& Deniz, H., \& Kaya, E., \& Yesilyurt, E. (2017, June), Board \# 98 : High School Science Teachers' Views of Nature of Engineering and Application of Engineering Design Practices (Work In Progress) Paper presented at 2017 ASEE Annual Conference \& Exposition, Columbus, Ohio. https://peer.asee.org/27967

[8] Marti, E. J., \& Kaya, E., \& Deniz, H., \& Yesilyurt, E., \& Iglesias, J. (2018, June), Assessing High School Science Teachers' Nature of Engineering (NOE) Perceptions with an Open-ended NOE Instrument (Fundamental) Paper presented at 2018 ASEE Annual Conference \& Exposition, Salt Lake City, Utah. https://peer.asee.org/29821

[9] Pleasants J, Olson JK. What is engineering? Elaborating the nature of engineering for K-12 education. Science Education. 2018;1-22. https://doi.org/10.1002/sce.21483 
[10] Katehi, L., Pearson, G., \& Feder, M. (2009). Engineering in the K-12 education. Understanding the states and improving the prospects (Vol. 16). Washington, DC: National Academic Press. Early Childhood Education and Practice.

[11] NGSS Lead States. "Next Generation Science Standards: For states, by states”. Washington, DC: The National Academies Press. 2013

[12] Lederman, N. G., Abd-El-Khalick, F., Bell, R. L., \& Schwartz, R. S. (2002). Views of nature of science questionnaire: Toward valid and meaningful assessment of learners' conceptions of nature of science. Journal of research in science teaching, 39(6), 497-521.

[13] Deniz, H., Yesilyurt, E., Kaya, E., Trabia, M. (2017, April). The Influence of an Authentic Engineering Design Experience on Elementary Teachers' Nature of Engineering Views. Paper presented at 2017 National Association for Research in Science Teaching (NARST) Annual International Conference, San Antonio, Texas.

[14] Deniz, H., Yesilyurt, E., Kaya, E. (2017, April). The Influence of an Authentic Engineering Design Experience on Elementary Teachers' Engineering Teaching Efficacy Beliefs. Poster presented at 2017 National Association for Research in Science Teaching (NARST) Annual International Conference, San Antonio, Texas.

[15] Riggs, I. M., \& Enochs, L. G. (1990). Toward the development of an elementary teacher's science teaching efficacy belief instrument. Science Education, 74(6), 625-637.

[16] Yesilyurt, E., Deniz, H., Kaya, E. (2019, January) Exploring Upper Elementary Students’ Nature of Engineering Views with Authentic Engineering Design Challenge. Paper Presented at the 2019 Association for Science Teacher Education Conference. Savannah, GE, USA.

[17] Fink, L. D., Ambrose, S., \& Wheeler, D. (2005). Becoming a professional engineering educator: A new role for a new era. Journal of Engineering Education, 94(1), 185-194.

[18] Glasson, G. E., \& Bentley, M. L. (2000). Epistemological undercurrents in scientists' reporting of research to teachers. Science Education, 84(4), 469-485.

\section{Appendices}

Appendix A. Descriptions of Nature Of Engineering Aspects (Retrieved from https://peer.asee.org/assessing-high-school-science-teachers-nature-of-engineering-noe-perceptions-with-an-openended-noe-instrument-fundamental)

\begin{tabular}{|l|l|}
\hline NOE Aspect & Description \\
\hline $\begin{array}{l}\text { Demarcation criteria (What is } \\
\text { engineering? What makes } \\
\text { engineering different from } \\
\text { other disciplines?) }\end{array}$ & $\begin{array}{l}\text { Engineering is systematically engaging in the practice of } \\
\text { design to achieve solutions for specific problems. Engineers } \\
\text { apply their understanding of the natural world (scientific } \\
\text { knowledge) to design solutions for real world problems. } \\
\text { This endeavor results in new technologies. }\end{array}$ \\
$\begin{array}{l}\text { In the K-12 context, "science" is generally taken to mean } \\
\text { the traditional natural sciences: physics, chemistry, biology, } \\
\text { and (more recently) earth, space, and environmental } \\
\text { sciences... } \\
\text { We use the term "engineering" in a very broad sense to } \\
\text { mean any engagement in a systematic practice of design } \\
\text { achieve solutions to particular human problems. Likewise, } \\
\text { we broadly use the term "technology to include all types of } \\
\text { human-made systems and processes-not in the limited sense } \\
\text { often in schools that equates technology with modern }\end{array}$ \\
\hline
\end{tabular}




\begin{tabular}{|c|c|}
\hline & $\begin{array}{l}\text { computational and communications devices. Technologies } \\
\text { result when engineers apply their understanding of natural } \\
\text { world and of human behavior to design ways to satisfy } \\
\text { human needs and wants. (NRC, 2012, pp. 11-12) }\end{array}$ \\
\hline Engineering design process & $\begin{array}{l}\text { The core idea of engineering design includes three } \\
\text { component ideas (NGSS Lead States, 2013): Define, } \\
\text { Design, and Optimize } \\
\text { A. Define: Defining and delimiting engineering problems } \\
\text { involves stating the problem to be solved as clearly as } \\
\text { possible in terms of criteria for success and constraints or } \\
\text { limits. } \\
\text { B. Develop Solutions: Developing solutions to } \\
\text { engineering problems begin with generating a number of } \\
\text { possible solutions. These potential solutions are then } \\
\text { evaluated to assess which ones best meet the criteria and } \\
\text { constraints of the problem. } \\
\text { C. Optimize: Optimizing the design solution involves a } \\
\text { process in which solutions are systematically tested and } \\
\text { refined and the final design is improved by trading off less } \\
\text { important features for those that are more important. }\end{array}$ \\
\hline Empirical basis & $\begin{array}{l}\text { Engineers optimize their design solutions and compare } \\
\text { alternative solutions based on evidence obtained from test } \\
\text { data. They use assumptions to produce simplified models } \\
\text { that does not contain the variables that the problem are } \\
\text { insensitive to. }\end{array}$ \\
\hline Tentativeness & $\begin{array}{l}\text { Phases of engineering design process do not always follow } \\
\text { in order, any more than do the "steps" of scientific inquiry. } \\
\text { At any phase, a problem solver can redefine the problem or } \\
\text { generate new solutions to replace an idea that is just not } \\
\text { working out. }\end{array}$ \\
\hline Creativity & $\begin{array}{l}\text { Creativity and imagination of engineers play a major role } \\
\text { during the engineering design process. The role of creativity } \\
\text { and imagination is not limited to any specific phase of the } \\
\text { engineering design process. }\end{array}$ \\
\hline
\end{tabular}




\begin{tabular}{|l|l|}
\hline Subjectivity & $\begin{array}{l}\text { There is no unique solution to an engineering design } \\
\text { problem. While there can be many solutions to the same } \\
\text { problem, some of these solutions may be more suited to } \\
\text { meet the criteria and constraints of the problem. }\end{array}$ \\
\hline Social aspects of engineering & $\begin{array}{l}\text { Engineering is not a solitary pursuit. Engineering design } \\
\text { solutions are constructed through social negotiation. } \\
\text { Despite their individual differences, members of an } \\
\text { engineering community share common understandings, } \\
\text { traditions, and values. This social dimension enhances the } \\
\text { quality of engineering design solutions. }\end{array}$ \\
\hline $\begin{array}{l}\text { Social and cultural } \\
\text { embeddedness }\end{array}$ & $\begin{array}{l}\text { Engineering is a human activity. There is a continued } \\
\text { interaction between engineering and society. Sociocultural } \\
\text { factors influence the engineering design process, and in } \\
\text { turn, engineering influences the society. These social and } \\
\text { cultural factors include social composition, religion, } \\
\text { worldview, political, and economic factors. }\end{array}$ \\
\hline
\end{tabular}

Appendix B. Nature of Engineering Questionnaire Items

- What, in your view, is engineering? What makes engineering different from other disciplines (e.g., science, philosophy, religion)? Illustrate your answer with an example.

- How do you define the work of an engineer? What do engineers do? Illustrate your answer with examples from your own work.

- What is an engineering design process? Give examples of steps in the design process.

- Do engineers follow the steps of the engineering design process in a linear format?

- If yes, explain why. Give an example to defend your position.

- If no, explain why. Give an example to defend your position.

- After engineers have developed an engineering design does the design ever change?

- If you believe that engineering designs do not change, explain why. Defend your answer with examples.

- If you believe that engineering designs do change, explain why. Defend your answer with examples.

- Does engineering design require testing?

- If yes, explain why. Give an example to defend your position.

- If no, explain why. Give an example to defend your position.

- Do engineers use their creativity and imagination during the engineering design process? If yes, then at which stages of the engineering design process do you believe that engineers use their creativity and imagination: identifying the problem; developing the design conceptually; constructing the design, testing the design; refining the design?

$\circ$ Please explain why engineers use creativity and imagination. Provide examples if appropriate. 
- If you believe that engineers do not use creativity and imagination, please explain why. Provide examples if appropriate.

- How do engineers do their work? Do they work alone or in groups?

- If alone, explain why. Give an example to defend your position.

- If in groups, explain why. Give an example to defend your position.

- Some claim that engineering is infused with social and cultural values. That is, engineering reflects the social and political values, philosophical assumptions, and intellectual norms of the culture in which it is practiced. Others claim that engineering is universal. That is, engineering transcends national and cultural boundaries and is not affected by social, political, and philosophical values, and intellectual norms of the culture in which it is practiced.

$\circ$ If you believe that engineering reflects social and cultural values, explain why and how. Defend your answer with examples.

- If you believe that engineering is universal, explain why and how. Defend your answer with examples.

- There is a variety of mobile phones commercially available in the market (e.g. iPhone, Galaxy, Huawei Mate, Nokia). Can there be a single best design for a smartphone?

$\circ$ If you believe that there is a single best design for a smartphone, please explain why.

- If you believe that there is not a single best design for a smartphone, please explain why.

Appendix C. NOE Aspects Scoring Rubric (Retrieved from https://peer.asee.org/board-98-high-schoolscience-teachers-views-of-nature-of-engineering-and-application-of-engineering-design-practices-work-in-progress)

\begin{tabular}{|l|l|}
\hline \multicolumn{1}{|c|}{ Description } & Point \\
\hline $\begin{array}{l}\text { No answer, incomprehensible or irrelevant } \\
\text { answer, or an answer could not be } \\
\text { categorized }\end{array}$ & 0 points \\
\hline $\begin{array}{l}\text { An answer that is not aligned with the } \\
\text { description of NOE aspect }\end{array}$ & 1 point \\
\hline $\begin{array}{l}\text { An answer that is partially aligned with the } \\
\text { description of NOE aspect }\end{array}$ & 2 points \\
\hline $\begin{array}{l}\text { An answer that is fully aligned with the } \\
\text { description of NOE aspect }\end{array}$ & 3 points \\
\hline $\begin{array}{l}\text { An answer that is fully aligned with the } \\
\text { description of NOE aspect. The view is well- } \\
\text { articulated and/supported with relevant } \\
\text { example(s) }\end{array}$ & 4 points \\
\hline
\end{tabular}


